\title{
Correspondence
}

\section{Inhaled nitric oxide as a coadjuvant therapy after massive pulmonary embolism}

To the Editor:

Woodward et al. reported an interesting case of massive pulmonary embolism occurring in a labouring patient. ${ }^{1}$ She was initially treated with oxygen and heparin and an urgent Cesarean section was indicated under general anesthesia. Hemodynamic collapse occurred ten minutes after delivery of an severely asphyxiated baby and a surgical pulmonary embolectomy was performed.

We would like to suggest the use of inhaled nitric oxide (iNO) as a coadjuvant therapy in this critical setting. Some experimental data show that the right heart failure and circulatory shock after a massive air embolism were attenuated when iNO was administered to dogs. ${ }^{2}$ In addition, iNO therapy improved oxygenation and had beneficial hemodynamic effects in four patients with severe pulmonary embolism. ${ }^{3}$ Besides the selective pulmonary vasodilation caused by $\mathrm{iNO}$, NO inhalation may diminish additional clot formation when emboli reach the lungs. ${ }^{4}$ Although the relevance of these findings remains to be elucidated, ${ }^{5}$ we believe that iNO therapy may attenuate the circulatory collapse and decrease the high mortality rate after massive pulmonary embolism.

Jose Eduardo Tanus-Santos MD PhD

Heitor Moreno Jr MD PhD

Campinas, Brazil

\section{References}

1 Woodward DK, Birks RJS, Granger KA. Massive pulmonary embolism in late pregnancy. Can J Anaesth 1998; 45: 888-92.

2 Tanus-Santos JE, de Nucci G. Low-dose inhaled nitric oxide attenuates hemodynamic changes following pulmonary air embolism in dogs. Anesth Analg 1998; 86: S155.

3 Capellier G, Jacques T, Balvay P, Blasco G, Belle E, Barale $F$. Inhaled nitric oxide in patients with pulmonary embolism. Intensive Care Med 1997; 23: 1089-92.

4 Gries $A$, Bode $C$, Peter $K$, et al. Inhaled nitric oxide inhibits human platelet aggregation, P-selectin expression, and fibrinogen binding in vitro and in vivo. Circulation 1998; 97: 1481-7.
5 Tanus-Santos JE. Inhaled nitric oxide and pulmonary embolism (Letter). Intensive Care Med 1998; 24: 747-8.

\section{Upper Airway Obstruction}

To the Editor:

Once in a great while in the past I have experienced, and I have observed others to experience, problems during the performance of awake fibreoptic-endoscopy aided tracheal intubation similar to those reported by Drs. McGuire and El-Beheiry. ${ }^{1}$ Even though glycopyrrolate was used, the fundamental problem has always seemed to be caused by/related to difficulty in handling excessive perilaryngeal fluid (the topicalized local anesthetic and/or secretions) (as in both of the authors' case reports). The perilaryngeal fluid may cause mechanical blockage of the airway, and/or induce laryngospasm, prolonged exhalation, coughing and gagging. As a result of these observations I have made a simple change in my practice which has greatly minimized these problems and difficulties. I instruct the patient, prior to the procedure, that I will anesthetize the upper airway mucosa by spraying a local anesthetic for ten seconds at a time and during and after the spraying of the local anesthetic the patient should gargle whatever fluid accumulates in the back of the throat. I then ask the patient to bring all the fluid to their lips, through which I insert a Yankauer suction catheter and remove all the fluid. The ten second spray-gargle-suction sequence clears the airway every ten seconds and the gargle-suction components are accomplished mainly in breath-hold or exhalation phases (as opposed to an inspiratory phase). In addition, the removal of the local anesthetic may decrease postoperative nausea and vomiting. ${ }^{2}$ Since I have instituted this practice $(n=\sim 200$ patients), ${ }^{2}$ I have had none of the problems reported by Drs. McGuire and El-Beheiry.

Jonathan L. Benumof MD

San Diego, California, USA

\section{References}

$1 \mathrm{Mc}$ Guire G, El-Beheiry $H$. Complete upper airway obstruction during awake fibreoptic intubation in patients with unstable cervical spine fractures. Can J Anesth 1999; 46: 176-8. 